International Journal of Linguistics, Literature and Culture
Available online at https://sloap.org/journals/index.php/ijllc/
Vol. 7, No. 3, May 2021, pages: 130-138
ISSN: 2455-8028
https://doi.org/10.21744/ijllc.v7n3.1486

\title{
Semantic Deviation in Arabic and English Proverbs of Love
}

\author{
Zahraa Abed Hashem ${ }^{\text {a }}$ \\ Thulfiqar Hussein Muhi ${ }^{\text {b }}$
}

Article history:

Submitted: 9 February 2021

Revised: 29 March 2021

Accepted: 18 April 2021

\section{Keywords:}

cultural wisdom; didactic function; idiomatic expressions; proverbs; semantic deviation;

\begin{abstract}
Proverbs are a type of idiomatic expressions that are commonly used in everyday spoken language. They concisely and figuratively summarize everyday experiences and common observations (Borowska, 2014). The proverbs of love often contain various stylistic features that are worthy of analysis. The present paper hypothesizes that semantic deviations in the Arabic and English proverbs of love facilitate pleasurable and enjoyable delivery of the didactic messages conveyed by these proverbs and maximize their persuasive effects. Semantic deviations (such as simile, metaphor, metonymy and synecdoche) represent an important type of stylistic deviation in proverbs because of their figurative features and aesthetic values. Such stylistic devices make the content of these proverbs more appealing the audience and maximize the persuasive effect of their contents. This study examined 50 proverbs of love (25 in each language) from stylistic perspective, based on the semantic deviation model developed by Leech (1969). The analysis showed that the extensive use of various types of semantic deviations maximize the persuasive effects, and eventually efficient transmission of cultural wisdom. Additionally, such deviations were found to reinforce and facilitates the pleasurable delivery of the didactic function of proverbs.
\end{abstract}

International journal of linguistics, literature and culture (C) 2021. This is an open access article under the CC BY-NC-ND license (https://creativecommons.org/licenses/by-nc-nd/4.0/).

\section{Corresponding author:}

Hashem, A. B.

M.A. Student, Department of English Language and Literature, College of Arts, Mustansiriyah University, Iraq

Email address: zahraaabed824@gmail.com

${ }^{a}$ M.A. Student, Department of English Language and Literature, College of Arts, Mustansiriyah University, Iraq

${ }^{\mathrm{b}}$ Assistant Professor, Department of English Language and Literature, College of Arts, Mustansiriyah University, Iraq 


\section{Introduction}

Proverbs are a type of idiomatic expressions that are commonly used in everyday spoken language, transmitted from one generation to another by words until they are recorded and became a treasure of folklore for future generations (Karagiorgos, 1999; Groussard et al., 2010). They concisely and figuratively summarize everyday experiences and common observations (Borowska, 2014). Proverbs are often considered to be "traditional items of folklore" (Norrick, 1985; Agyekum, 2021).

Proverb of love is a type of proverb, which is said to show the reality of love as experienced by people and to give people advices on how to deal with love. Stylistically, such proverbs involve various types of deviations, e.g., phonological, graphological, lexical, syntactic, semantic. Such stylistic features often influence the reader's (listener's) interpretation and appreciation of these conventionalized linguistic forms.

In this context, the paper aims to understand how different types of stylistic devices, more specifically the semantic deviations, such as simile, metaphor, metonymy, synecdoche, oxymoron and hyperbole are employed in the Arabic and English proverbs of love. To that end, the paper hypothesizes that proverbs contain different types of semantic deviations serve facilitating pleasurable and enjoyable delivery of the didactic messages conveyed by these proverbs and maximizing their persuasive effects. The paper proceeds as follows. Section 2 presents the theoretical background. Section 3 presents data and methodology. Section 4 provides the results. Finally, section 5 presents the main conclusions.

\section{Theoretical Background}

\section{Deviation}

In stylistics, the concept of deviation refers to a violation of the rules or conventions of a language. The concept of deviation is very important in the study of style because texts may become stylistically special and peculiar when they deviate from standard norm of language. This norm is either absolute (as norm that is related to the whole language), or it is relative (as norm that is related to some set of texts) (Enkvist, 1985).

As Aquilina (2014) argues that "the term deviation may refer to a veer from the norms of language as a whole, or it may refer to the norms of literary composition and even those within a particular text". Deviation is one of the strategies of foregrounding which indicates linguistic moves away from the norms (Stockwell \& Whiteley, 2014; Menninghaus et al., 2015). Text might be veered away from an "external or internal norm". According to Crystal (2008: 134) deviation can be made at the level of the sentence, or any other unit that deviates from the rule and it appears "grammatically, phonologically, or even semantically ill-formed".

Besides, Leech (1969) indicates that deviation can produce fascinating and surprising elements. He (ibid: 59-60) also adds that a linguistic deviation can be "artistically significant" if it is first, communicates something, second, communicates the intended meaning of author and third, if it is felt by the reader to be important.

Deviant forms can be classified across different levels of analysis. Leech (1969) presents different types of linguistic deviation distinguished threat the levels of "realization, form, and semantics". Realization includes "phonology and graphology"; form contains "grammar and lexicon"; while semantics comprises "denotative or cognitive meaning". As illustrated below:

Table 1

Types of deviation

\begin{tabular}{|l|l|l|l|}
\hline Realization & Form & Semantics & \\
\hline Phonology & $\begin{array}{l}\text { (Grammar and } \\
\text { Lexicon) }\end{array}$ & $\begin{array}{l}\text { (Denotative or Cognitive } \\
\text { Meaning) }\end{array}$ \\
\hline Graphology & (Adoped from Lech, & \\
\hline
\end{tabular}

(Adopted from Leech, 1969)

Based on this categorization, Leech (1969) introduces different kinds of linguistic deviation including: phonological, graphological, lexical, syntactic, semantic deviations.

Hashem, Z. A., \& Muhi, T. H. (2021). Semantic deviation in Arabic and English proverbs of love. International Journal of Linguistics, Literature and Culture, 7(3), 130-138. https://doi.org/10.21744/ijllc.v7n3.1486 


\section{Phonological Deviation}

Phonological deviation is the mispronunciation of a sound or syllable that may happen deliberately in order to maintain rhyme and meter, for example, pronouncing the noun 'wind' like the verb 'wind'. According to Leech (1969), phonological deviations involve "irregularities of pronunciation".

\section{Graphological Deviation}

Graphological deviation can be defined as deviation on "the form of word" (Widayanti, 2014; Honeck, 1973). As Leech (1969) mentions, "any strangeness of the written form would be classified as a form of graphological deviation", which comprises the arrangement of the words in writing text, the use of spelling, punctuation, capitalization, hyphenation, italization and so on (Burke, 2014; Lawal et al., 1997).

\section{Lexical Deviation}

Lexical deviation is "the violation of lexical rule" that is related to neologism. Neologism is the new word which is presented into language. One important example of neologism is a nonce-formation that is the creation of new words.

\section{Syntactic Deviation}

Syntactic deviation is "transformational operations of addition, deletion, rearrangement and replacement of syntactic components", which are most popular in literary work and also proverbs (Plett, 2010).

\section{Semantic Deviation}

Semantic deviation is the deviation of meaning. It means that the senses of the "words, phrases, or sentences" are ambiguous (Widayanti, 2014).

\section{Semantic Deviation}

Semantic deviation is an important level of linguistic deviation because of its figurative language that is the heart of literary work. Leech (1969) argues that semantic deviation can be interpreted as 'non-sense' or 'absurdity'. Leech (1969) identifies several types of semantic deviations. The first type consists of semantic oddity (transference) and honest deception. Semantic oddity is more popular in literary work which is transference of meaning. In other words, it is the conversion from literal meaning to figurative meaning. Semantic oddity consists of different types of figurative language: metaphor (including personification), metonymy (including synecdoche), Simile, tautology, and oxymoron. "Metaphor is the most important figure of speech, in which one thing, idea, or action is referred to by a word or expression normally denoting another thing, idea, or action" (Baldick, 2001), and it is more popular in literary work and also in a proverb. The examples below showcase semantic deviations in Arabic and English proverbs:

1. Love is blind (metaphor)

2. (metaphor)

In these proverbs literal meaning are transferred to figurative meanings by using metaphors, and specifically personifications. In both languages, love is compared to the blind person by using the word blind to refer to the idea that if someone falls in love cannot see the faults of beloved. So these proverbs semantically deviate from the literal meaning to indicate a specific understanding of love. Metonymy is the other figure of speech that uses "the name of one thing for that of something else with which it is associated" (ibid.). On the other hand, synecdoche, which is special type of metonymy, is defined as "a rule of applying the term for the part to the whole" (Li \& Shi, 2015). And

3. Everybody loves a lord. (metonymy) 
In example (3) the word 'lord' is used to symbolize power and money, which attracts love and respect. Thus, the word lord refers to richness and power. Simile is other type of semantic oddity which "involves an explicit comparison between two things or actions. The majority of similes include the word 'like' (Cruse, 2006). Consider the love proverb below:

4. Love is like war, Easy to start, hard to end, impossible to forget.

In example (4) above includes an explicit comparison between love and war by using the word 'like'. It means that love and war share same characteristics and they are easy to start but so hard to end. Tautology is other type of semantic oddity where the same thing is said twice but in different way. It is the repetition or duplication of words. Such case is depicted in the following proverb:

\section{Love begets love.}

The word "love" is repeated twice in the proverb which makes the proverb ambiguous for the listener. Oxymoron is also considered to be one of the semantic deviations where two opposite terms or phrases are integrated into one sentence as exhibited in the proverb: "Love makes a wit of the fool". The other type of semantic deviation is "honest deception" which involves a form of "misrepresenting the truth" (Prafitri \& Suhatmady, 2014). Honest deception includes hyperbole and litotes (ibid.). The term 'honest deception' is paradoxical because it is not really deception but it is used by literary writers for emphasis (Fowler, 1926 cited by Li \& Shi, 2015). In this respect, Leech (1969) indicates that these tropes are related to each other since all of them misrepresent the truth. Thus, hyperbole distorts truth by saying too much (figure of speech of overstatement) as exhibited in the proverb: "In a thousand pound of Law there's not an ounce of love" wherein reality is exaggerated.

\section{Data and Methodology}

The paper analyzes 50 proverbs of loves in Arabic and English ( 25 from each language). These proverbs are collected from different Arabic and English proverbs collections and dictionaries. Analyzing data from different languages (Arabic and English) aims to investigate how the stylistic features, i.e. semantic deviation effect on the didactic function of proverbs in both English and Arabic love proverbs. Methodologically, the analysis will focus on the different types of semantic deviations (tropes) in both datasets. In this respect, the study will draw on model of Leech (1969). The data analysis will be done across different types of semantic deviation, including: metaphor, personification, metonymy, synecdoche, Simile, tautology, oxymoron, and hyperbole.

\section{Results and Discussions}

\section{Semantic deviation}

In order to analyze the semantic deviations, the researcher coded the two datasets in terms of the six main types of semantic deviations, drawing on Leech (1969). The overall results are summarized in Table (2) below:

Hashem, Z. A., \& Muhi, T. H. (2021). Semantic deviation in Arabic and English proverbs of love. International Journal of Linguistics, Literature and Culture, 7(3), 130-138. https://doi.org/10.21744/ijllc.v7n3.1486 
Table 2

The frequency of semantic deviation

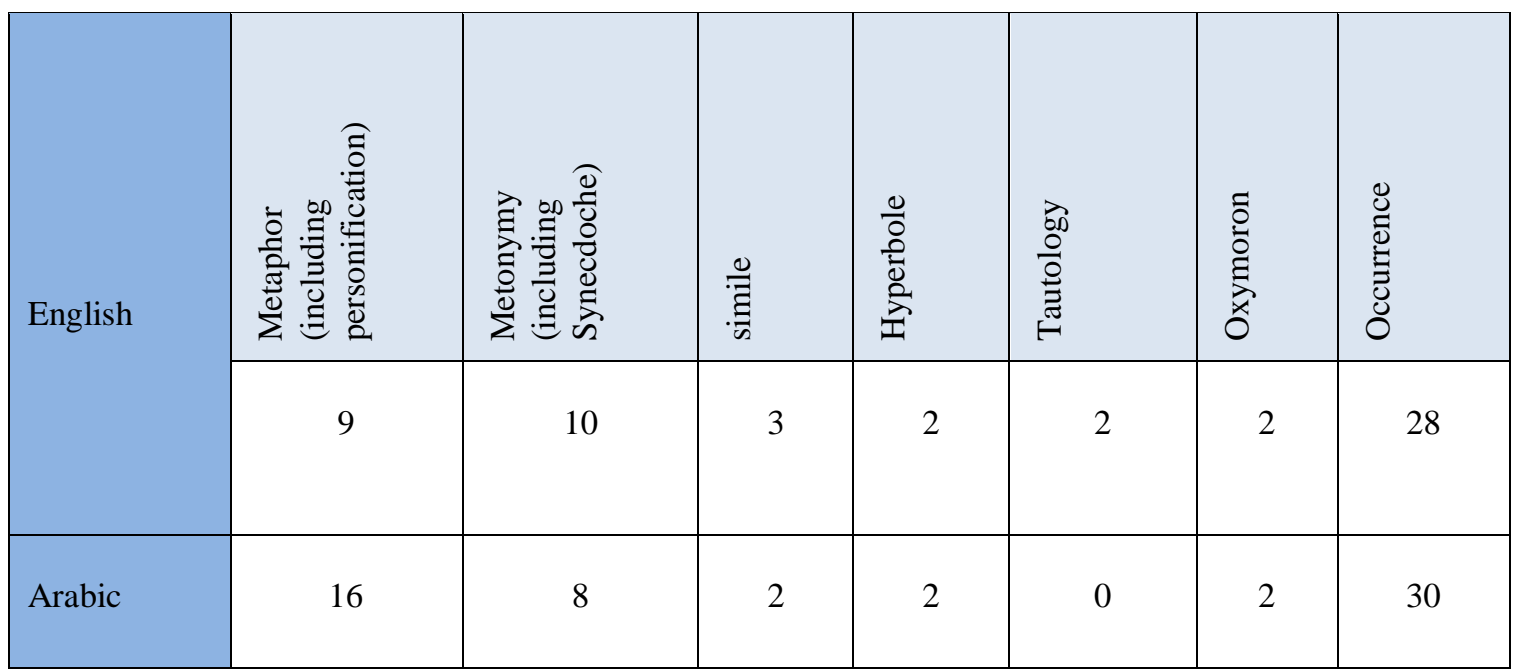

From a quantitative perspective, and as shown in table (2) above, the Arabic dataset includes (30) semantic deviations which makes semantic deviation in Arabic proverb much more frequent than in the English dataset, as it includes (28) token of semantic deviation. Table (2) reveals that metaphor, with (16) token identified, is the most frequently used type of semantic deviation in the Arabic love proverbs, whereas tautology is totally absent in the data. On the other hand, metonymy in the English dataset is the most frequently used type of semantic deviation, with (10) token identified, while hyperbole scores the least frequency with (2) token identified. From a contrastive perspective, the results indicate that metonymy is more commonly used in the English love proverbs than in their Arabic counterparts, whereas metaphor is more common in the Arabic love proverbs. Examples of these types of semantic deviations from the two datasets are given below:

\section{Metaphor}

6. "Marriage is a lottery" (metaphor)

7. " (الزواج قسمة و نصيب" (metaphor)

The proverb in example (6) metaphorically shows us that 'marriage' is like a 'lottery', which is based on luck whether it fails or succeeds. Similarly, Arabic proverb in example (7) includes a similar metaphor which compares marriage with a person's destiny and luck. In this type of semantic deviation, different things or ideas, such as 'marriage and lottery', are brought together to create implicit comparisons and analogies that make the logemes (Chesnokova, Savenkova (2002), and Polinichenko (2004)) communicated by proverbs more persuasive and convincing. In both English and Arabic, the concept of marriage can be understood through the concept of lottery to highlight its unpredictability. The analysis reveals that there is mapping process between two different domains, i.e. the target and source. Target domain (the concept which we want to identify by the metaphor), and source domain (the concept which is used to make the metaphorical construction). Thus, in "marriage is a lottery", and " الزواج قسمة و (ج) a نصيب", marriage (الزواج) is the target domain and the concept of lottery (قسمة و نصيب) is a source domain in which transfers characteristics (lucky, unlucky, fails or succeeds) from the source "lottery" in order to frame them in the concept of "marriage" (target domain), which eventually underscores the unpredictability and incalculability of marriage. A special type of metaphorical expressions was also identified in the data; this type is commonly known as personification in the traditional study of tropes. Consider examples below:

8. "Love is blind" (personification)

9. "ان الهوى شريك العمى" (personification) (Passion is a partner of blindness) 
The use of personification is obvious in the example (8) where love as an inanimate object holds an animate feature, i.e. that of human being. In this proverb, love is personified as a blind person who is unable to find his or her way or to see the faults of his/her lover. Likewise, in the Arabic proverb in example (9), passion and blindness are treated as human beings, depicted as sharing the common feature of not seeing the world in the right perspective. In these proverbs, the literal meanings are transferred to the figurative meanings where the inanimate objects (love, passion, and blindness) carry human characteristics. The use of such personifications can give rise to implicit analogies that have powerful persuasive effects.

\section{Metonymy}

Another type of semantic deviation found in the two datasets is metonymy where the name of one thing is used to refer to other thing or idea. Consider the example below:

10. "Everybody loves a lord". (metonymy)

11. "بصلة المحب خروف" (metonymy) (The loving person's onion is a lamb.)

In example (10) the word 'lord' is used to symbolize power and money, which attracts love and respect. Thus, the word lord refers to richness and power. Comparatively, in example (11) the word (بصلة/ onion) is brought together with the word (خروف lamb) to refer to the significance of love in relationships. In this proverb, 'onion', which symbolizes the cheapest meal, can be satisfying and pleasurable as 'lamb', which refers to a fine meal served at large banquets, if love is there. A special type of metonymic expressions was also identified in the data; this type is commonly known as synecdoche in the traditional study of tropes. The example below showcases how synecdoche is used in both datasets.

12. "When the wolf comes in at the door, love creeps out of the window". (synecdoche)

"إن دخل الفقر من الباب، خرج العب من الثباكت" 13

"When poverty comes in at the door, love flies out of the window"

Synecdoche is a specific type of metonymy where a part of something can stand for the whole. In example (12), synecdoche is used to emphasize that parts of the house in which 'door' and 'window' stand for 'home'. Moreover, this example also contains a metonymic expression where the word 'wolf' is used to symbolizes hardships or poverty, highlighting the fact that when lovers (couples) are poor or face hardship in their live, their love will fade away. The analysis also shows that synecdoche is commonly used in the Arabic proverbs of love. As seen in (13), the word الباب, the door) is not used specifically as a part of the house, but it is referred to the house itself. Similarly, the word (الشباكا', the window) is not used to refer to the window itself but rather to the house as a whole. This proverb explains the hard path that a loving couple has to go through in their life journey when they do not have enough money.

\section{Simile}

Like metaphors, similes are based on bringing together two entities in order to highlight some kind of connection or analogies, but such a connection is made explicit by using words such as: 'as' or 'like'. Consider the examples below:

14. "Inconstant as a woman's love".

15. "ضرب الحبيب مثثل اكل الزبيب"

"Being beaten by a lover is like eating raisins".

In example (14) above includes an explicit comparison between an inconstant person and a woman's love by using the word 'as'. It means that $\mathrm{s} /$ he is logical in his/her view like a woman whose heart is changeable. Likewise, the words (sic) are used in Arabic to make a direct connection between two entities used in simile, as shown in example (15), which explicitly links between hitting of beloved person to eating raisins by using the word (من/ like). Hyperbole

Hashem, Z. A., \& Muhi, T. H. (2021). Semantic deviation in Arabic and English proverbs of love. International Journal of Linguistics, Literature and Culture, 7(3), 130-138. https://doi.org/10.21744/ijllc.v7n3.1486 
Hyperbole is another type of semantic deviation found in love proverbs where there is an exaggerated statement. The examples below showcase typical use of hyperbole in English and Arabic proverbs:

16. "Love will go through stone walls". (Hyperbole)

17. "روحان في الجسد" (Hyperbole)

(Two souls in one body)

In example (16), there is an exaggeration in describing the power of love which can pass stone walls. Likewise, in the Arabic proverb presented in example (17), a state of inseparable love between two lovers incredibly described as having two souls contained in a single body. In plain words, this proverb uses hyperbole to show a relationship between two persons deeply related to each other so that they cannot be separated.

\section{Tautology}

Tautology is another semantic deviation exploited in love proverbs where the same thing is said twice in the proverb. It is the repetition or duplication of words. Consider the following English proverb of love:

\section{8. "Love begets love".}

The word "love" in the proverb above is duplicated which repeated the same meaning and it gives no information to the listener without the particular context. Such type of semantic oddity makes the proverb ambiguous. Here, the duplication of the word "love" helps to conveyance the message that "to win someone's heart, we must treat him or her with love". Tautological expressions have a powerful persuasive function as they invite the addressee(s) to reflect on the deep meanings implicitly communicated by them, which eventually makes the logemes communicated by the proverbs employing these tautologies convincing and entertaining.

\section{Oxymoron}

Another type of semantic deviation found in love proverbs is oxymoron, where two opposite terms or phrases are integrated into one sentence. In the following English and Arabic love proverbs, certain conflicting linguistic concepts can be seen:

19. "Love makes a wit of the fool".

20. "ما محبه الا بعد عداوة" (Love comes after enmity)

The proverb in example (19) juxtaposes two contradictory concepts, i.e. wit and fool. Here, two words (wit, fool), which contradict each other, are used in the single sentence. The juxtapositions of these two contradictory concepts are semantically odds and incompatible, but it is used to communicate the idea that the wit person becomes a fool when s/he falls in someone's love. This type of semantic oddity, which has self-conflicting information, can also be found in the Arabic dataset. As seen in (20), two words (love, hate) contradict each other in the same sentence to mean that, "That person you hate in the beginning may become your love or close friend afterward". The use of oxymoron makes these proverbs both entertaining and thought provoking.

\section{Result of Discussion}

The analysis of the English and Arabic proverbs of love conspicuously indicates that the proverbs of love contain unique features that make them distinct from everyday language. From a stylistic perspective, the proverbs of love have been shown to have many poetic features, including a wide range of tropes. These poetic features do not only make proverbs aesthetically valued, which ultimately facilitates pleasurable and enjoyable delivery of the didactic messages conveyed by these proverbs, but they also make them more persuasive and memorable. The use of these poetic features seems relatively similar across the two datasets. This is mainly because proverbs in both languages have a specific didactic function that aims to teach and instruct the addresses, and to transmit cultural wisdom and knowledge across time. Thus, they have to be phrased in a highly poetic and appealing way. As shown in the analysis 
the use of tropes reinforces didacticity through the use of explicit and implicit poetic comparisons and analogies (e.g. similes, metaphors, metonymies, etc.) with persuasive effects that aim to educate and inform the audience.

\section{Conclusion}

The analysis of deviation revealed that both datasets contain semantic deviation but they are much more frequent in Arabic proverbs than in the English dataset and this reflect the fact that Arabic love proverbs seemed more argumentative, though imaginative, than English owing to their overuse of figurative forms to convey the concept of love. As well, both datasets exhibited extensive use of various types of tropes (i.e. metonymy, metaphor, simile, hyperbole, etc.) to maximize powerful persuasive effects, and eventually efficient transmission of cultural wisdom. Thus, the use of such tropes was found to reinforce and facilitates the pleasurable delivery of the didactic function of proverbs.

Conflict of interest statement

The authors declared that they have no competing interests.

Statement of authorship

The authors have a responsibility for the conception and design of the study. The authors have approved the final article.

Acknowledgments

We are grateful to two anonymous reviewers for their valuable comments on the earlier version of this paper.

Hashem, Z. A., \& Muhi, T. H. (2021). Semantic deviation in Arabic and English proverbs of love. International Journal of Linguistics, Literature and Culture, 7(3), 130-138. https://doi.org/10.21744/ijllc.v7n3.1486 


\section{References}

Agyekum, K. (2021). Proverbs in Akan highlife lyrics: A case study of Alex Konadu's lyrics. Journal of Pragmatics, 174, 1-13. https://doi.org/10.1016/j.pragma.2020.12.016

Aquilina, M. (2014). The Event of Style in Literature. UK: Palgrave Macmillan.

Baldick, C. (2001). The Concise Oxford Dictionary of Literary Terms. Published in the United States by Oxford University Press Inc., New York.

Borowska, A. (2014). Introduction to Paremiology: A Comprehensive Guide to Proverb Studies. Published by De Gruyter Open Ltd, Warsaw/Berlin.

Burke, M. (Ed.) The Routledge Handbook of Stylistics. London: Routledge.

Cruse, A. (2006). A Glossary of Semantics and Pragmatics. Edinburgh University Press.

Crystal, D. (2008). A Dictionary of Linguistics and Phonetics. Oxford: Basil Blackwell. Sixth Edition.

Enkvist, N. E. (1985). Text and Discourse Linguistics, Rhetoric and Stylistics. In Van Dijk, T.(ed.). Discourse and Literature. Amsterdam: John Benjamins.

Groussard, M., Viader, F., Hubert, V., Landeau, B., Abbas, A., Desgranges, B., ... \& Platel, H. (2010). Musical and verbal semantic memory: two distinct neural networks?. Neuroimage, 49(3), $2764-2773$. https://doi.org/10.1016/j.neuroimage.2009.10.039

Honeck, R. P. (1973). Interpretive versus structural effects on semantic memory. Journal of Verbal Learning and Verbal Behavior, 12(4), 448-455. https://doi.org/10.1016/S0022-5371(73)80025-8

Karagiorgos, P. (1999). Greek and English Proverbs. Cambridge Scholars Publishing.

Lawal, A., Ajayi, B., \& Raji, W. (1997). A pragmatic study of selected pairs of Yoruba proverbs. Journal of pragmatics, 27(5), 635-652. https://doi.org/10.1016/S0378-2166(96)00056-2

Leech, G. (1969). A Linguistic Guide to English Poetry. London: Longmans.

Li, X., \& Shi, M. (2015). A Stylistic Study on the Linguistic Deviations in E. E. Cummings' Poetry. Shanghai International Studies University, China.

Menninghaus, W., Bohrn, I. C., Knoop, C. A., Kotz, S. A., Schlotz, W., \& Jacobs, A. M. (2015). Rhetorical features facilitate prosodic processing while handicapping ease of semantic comprehension. Cognition, 143, 48-60. https://doi.org/10.1016/j.cognition.2015.05.026

Norrick, N. R. (1985). How Proverbs Mean: Semantic Studies in English Proverbs. Mouton Publishers Berlin. New york. Amsterdam. Kassel University.

Plett, H. F. (2010). Literary Rhetoric Concepts-Structures-Analyses. Leiden, Boston: Brill.

Prafitri, W., \& Suhatmady, B. (2014). Semantic Deviation on William Blake`s Selected Poems. Universitas Mulawarman.

Stockwell, P., \& Whiteley, S. (2014). The Cambridge Handbook of Stylistics. University of Nottingham and University of Sheffield. University Printing House, Cambridge CB2 8BS, United Kingdom.

Widayanti, S. R. (2014). A Stylistic Study of Language Deviation in Thomas Hardy Poem. Universitas Widya Dharma Klaten. 